\title{
Where do human sperm and egg meet?
}

\author{
Liselot J W Thunnissen ${ }^{1}$, Cindy G J Cleypool ${ }^{2}$ and Bernadette S de Bakker ${ }^{1}$ \\ ${ }^{1}$ Department of Medical Biology, Section Clinical Anatomy \& Embryology, Amsterdam UMC, University of \\ Amsterdam, Amsterdam, The Netherlands and '2Division of Surgical Specialties, Department of Anatomy, University \\ Medical Center Utrecht, Utrecht University, Utrecht, the Netherlands
}

Correspondence should be addressed to B S de Bakker; Email: b.s.debakker@amsterdamumc.nl

\begin{abstract}
Summary
Although it is commonly accepted that fertilisation in humans occurs in the ampulla of the fallopian tube, the peritoneal cavity might represent an alternative fertilisation site. Studies substantiating both fertilisation sites were reviewed and new insights on the fertilisation site in humans are discussed, including their implications for reproductive medicine.

Reproduction (2021) $\mathbf{1 6 1}$ V1-V4
\end{abstract}

Infertility is defined as the absence of pregnancy after frequent unprotected sexual intercourse for a minimum of 12 months and affects $8-12 \%$ of western couples in their reproductive age (Van der Borght \& Wyns 2018). Since infertility has a significant psychosocial impact (Ombelet et al. 2008), assisted reproductive technology (ART) is frequently applied. However, ART is costly and has limited success rates (Farquhar \& Marjoribanks 2018). Understanding fundamental reproductive principles such as the site for fertilisation, and hence the optimal environment, might contribute to further ART optimisation.

It is commonly accepted that fertilisation in humans occurs in the ampulla of the fallopian tube as shown in Fig. 1A. Comparable images are widely depicted in study books, scientific publications and on the internet. However, one could question its accuracy since the reference to the original scientific data has become completely lost over time. So, is this representation of human fertilisation (Fig. 1A) still accurate? Are there any new scientific insights?

For this Point of View article, the most relevant studies discussing potential fertilisation sites in humans were reviewed, supplemented with new insights obtained from literature concerning cryo-preservation and reimplantation of ovarian tissue, and, endometriosis and infertility. By this, we aimed to create a more modern representation of the widely used image (Fig. $1 \mathrm{~A})$, according to the latest scientific insights on the fertilisation site in humans.

Reinier de Graaf (1641-1673), a Dutch physician and comparative anatomist was the first who described what is also known as the direct ovum-pick-up theory (reviewed by Burger 2009). He hypothesised that the fimbriae attach around the ovary to pick up the released ovum, from now on referred to as oocyte, after which it is transported to the uterus via the fallopian tube. This direct oocyte-pick-up theory was supported by the fact that infertile women with one fallopian tube and a contralateral ovary became pregnant after surgical conjunction of these structures (Dabirashrafi et al. 1996). Although at the time of de Graaf the existence of spermatozoa was still unknown, he speculated on fertilisation of the oocyte by zaaddamp (literally: seed vapour), which he thought to occur in the ovary, prior to oocyte pick up (De Graaf 1686). In time, the direct oocyte-pick-up theory persisted while the leading location for fertilisation became the ampulla. The ampulla as favourable site for fertilisation was further supported by a study investigating the transport and distribution of spermatozoa in human fallopian tubes obtained during total hysterectomy (Williams et al. 1993). In pre- and post-ovulatory patients, the number of spermatozoa within the ampullary region of the fallopian tube positioned on the site of the ovulating ovary was significantly higher than within the ampullary region of the contralateral tube. The authors concluded that fertilisation most likely occurs at the location were most spermatozoa reside: the ampulla (Williams et al. 1993).

Opposed to the ampulla, fertilisation might occur in the peritoneal cavity, a theory referred to as aquatic conception (Burger 2009), which from now on will be referred to as intraperitoneal conception. This idea was first suggested by Doyle (1951) who performed culdoscopy (i.e. endoscopic examination of the rectouterine pouch and pelvic viscera) in ovulating patients and observed the fimbriae to be suspending in the recto-uterine pouch and not wrapping themselves around the ovary. He concluded that the oocyte floats 

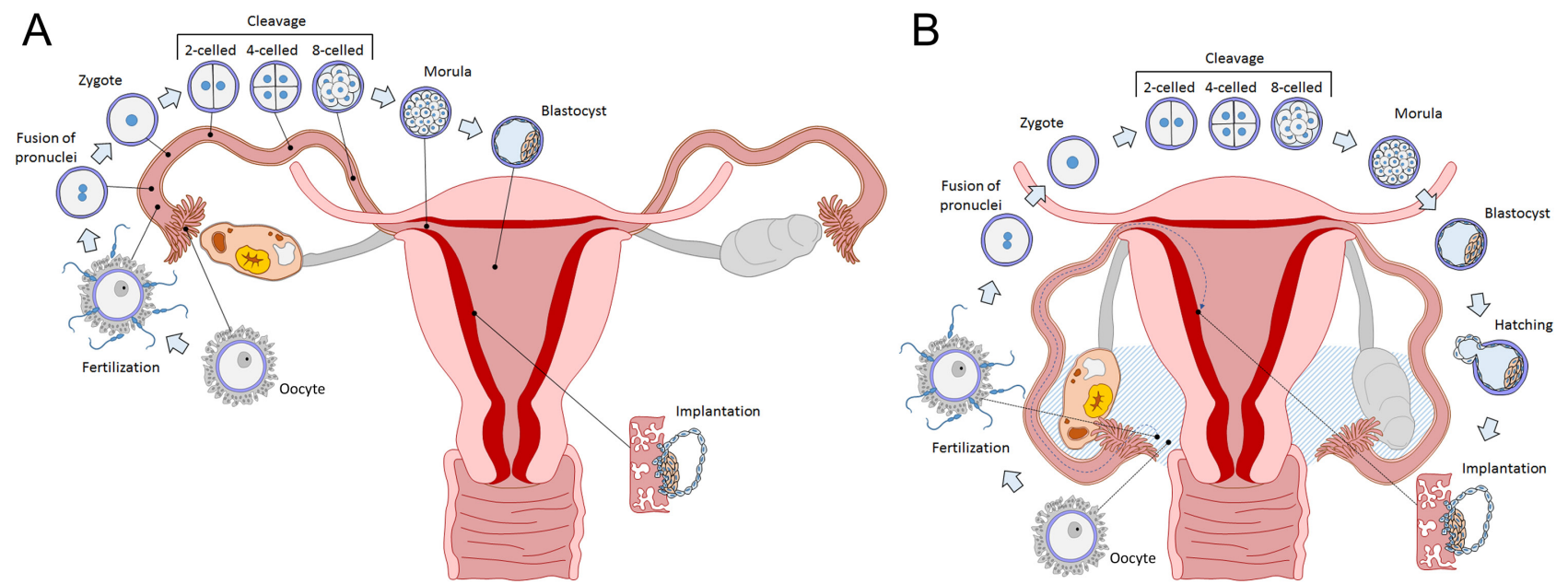

Figure 1 Dorsal view on the female internal reproductive organs, representing the two theories of fertilisation in humans. (A) Fertilisation in the ampulla of the fallopian tube. A quick search on Google Images on the words fertilization or implantation tells us that this image, showing fertilisation in humans, has now been copied dozens or even hundreds of times. This image has thereby become the standard educational model for professionals and laymen showing that human fertilisation takes place in the ampulla of the fallopian tube. The reference to the first original scientific image on which all of these images are based has become completely lost over time. (B) The intraperitoneal conception. The shaded area indicates the region of the recto-uterine pouch, where migration of both oocyte and spermatozoa might take place and even fertilisation can occur. The fimbriae are suspending in the recto-uterine pouch which enables them to pick-up the oocyte or fertilised egg. Theoretically, the oocyte can also be released by the contralateral ovary. Note that due to a gap in literature, no exact location can be marked for the location of the oocyte after ovulation (floating in the recto-uterine pouch?), the exact site of fertilisation (the recto-uterine pouch or the ampulla?), the processes of cleavage, hatching, and so on. The location of implantation into the endometrium was randomly marked to increase clarity of the figure, but it can occur over the complete coverage of the endometrium. The hatching stage was added to the figure for completion.

in the peritoneal fluid of the recto-uterine pouch and is eventually picked up by one of the fallopian tubes (Doyle 1951). In another study by Doyle et al. (1966), the oocyte was observed to be located in the fallopian tube contralateral to the ovary involving the corpus luteum (Doyle et al. 1966). This evidence is supported by published cases of ectopic tubal pregnancies contralateral to the corpus luteum. More cases have been described suggesting transperitoneal oocyte migration and supporting the theory that fertilisation occurs in the peritoneal cavity. For example, cases of ectopic abdominal pregnancies (Yildizhan et al. 2009), spontaneous pregnancies in the non-communicating rudimental horn of a bicornuate uterus (Ambusaidi \& Jha 2014) and spontaneous pregnancies in women with only one ovary and one contralateral fallopian tube (First 1954).

Another subject which could possibly contribute to our knowledge on oocyte migration, is ovarian transplantation. As chemo- and radiotherapy can be harmful for germ cells, ovarian tissue can be cryopreserved and transplanted to restore fertility after cancer therapy. Ovarian tissue autografts can be implanted to an heterotopic site (e.g. subcutaneously, in the forearm or abdominal wall) or an orthotopic site (i.e. the pelvic cavity, para-ovarian or intra-ovarian) (Donnez et al. 2006). In para-ovarian transplantation, ovarian tissue is placed in a subperitoneal pocket below the fallopian tube or next to the fimbriae. Interestingly, spontaneous pregnancies have been reported after this type of transplantation (Donnez et al. 2004, Van Der Ven et al. 2016), suggesting that the oocyte is able to transfer through the peritoneal cavity towards the fallopian tube. Transperitoneal migration of the oocyte can be a clue that fertilisation does not always happen the way we were taught and how it is illustrated in the most known image of fertilisation (Fig. 1A).

In addition to a transperitoneal migrating oocyte, intraperitoneal conception requires transperitoneal migrating spermatozoa. Templeton and Mortimer (1980) found spermatozoa in the peritoneal fluid after intracervical insemination or sexual intercourse. Interestingly, during this study, no pregnancies were established in women where spermatozoa were absent from the peritoneal fluid, which leads to the careful assumption that exposure of spermatozoa to peritoneal fluid might be a required physiological process for successful fertilisation. Further support for the fact that spermatozoa can thrive in peritoneal fluid and even result in vital pregnancies came from a study that investigated the rate of pregnancies after intraperitoneal insemination; ten women were inseminated, which resulted in three vital pregnancies (Forrler et al. 1986).

Based on the studies described previously one can conclude that independent transperitoneal migration of both oocyte and spermatozoa can occur and can even result in vital pregnancies. This, however, does not necessarily mean that both oocyte and sperm are in 
the peritoneal cavity at the same time and neither that fertilisation occurs prior to their transfer to the fallopian tube. To address this first issue, a study was performed in 59 patients wherein both sperm and oocytes were transferred into the recto-uterine pouch. This resulted in 18 pregnancies $(24 \%)$ out of the 74 cycles performed (Sharma et al., 1991). Although these 'oocyte and spermatozoa migration studies' do not contribute to our understanding of the location of fertilisation, they do support the idea that transperitoneal migration of gametes might be a physiological process.

In case of an intraperitoneal conception, both the oocyte and spermatozoa reside in the peritoneal fluid, which, therefore must represent the optimal environment for fertilisation. To confirm this assumption, fertility might be hampered in clinical conditions in which the composition of peritoneal fluid is altered. One such condition is endometriosis. Several research groups looked into the composition of peritoneal fluid from women with endometriosis and observed multiple proteins (e.g. complement C3, APCS, SERPINA1 and clusterin) to have a significantly higher expression in the peritoneal fluid of infertile women with endometriosis, than in the peritoneal fluid of fertile women with endometriosis (Ferrero et al. 2009). In addition to these proteins, infertility in women with endometriosis is associated with an increase in CD71 positive macrophages (Martínez-Román et al. 1997) and a diminished presence of the IL6 (Skrzypczak et al. 2005) in the peritoneal fluid. Studies in which spermatozoa are exposed in vitro to peritoneal fluid of infertile women with endometriosis showed that swimming-velocity and penetration-capacity of spermatozoa are negatively influenced (Aeby et al. 1996). It is possible, yet not certain, that peritoneal fluid alterations are caused by endometriosis and subsequently cause infertility.

Thus, both gametes can migrate through the peritoneal cavity and their simultaneous intraperitoneal presence can result in vital pregnancies. However, whether fertilisation occurs in the peritoneal cavity or after the transfer of both gametes to the fallopian tube, remains ambiguous. Indicative for the fact that fertilisation indeed can occur in the peritoneal cavity is the occurrence of intraperitoneal ectopic pregnancies, also referred to as abdominal pregnancies. In these pregnancies, the embryo implants into the peritoneum without signs that there was a tubal pregnancy first.

In conclusion, the question where fertilisation in humans exactly takes place, remains partly unanswered. The main theory of the fertilisation site being the ampulla of the fallopian tube (Fig. 1A), is opposed by the relatively unfamiliar theory that fertilisation occurs in the peritoneal cavity (Fig. 1B). Both have been proven to be possible, yet it is hard to confirm which site is the usual and which is the exception. Despite the lack of a valid conclusion, this study is the proof of a significant knowledge gap in human reproduction.
More research is needed, as better knowledge on the optimal fertilisation environment can potentially increase ART success.

\section{Declaration of interest}

The authors declare that there is no conflict of interest that could be perceived as prejudicing the impartiality of this point of view.

\section{Funding}

This work was supported by the De Snoo - van 't Hoogerhuijs Foundation.

\section{Author contribution statement}

L T performed the literature search and wrote the manuscript. C C conceived the study, wrote the manuscript and commented on the figure. B B conceived the study, wrote the manuscript and created the figure.

\section{References}

Aeby TC, Huang T \& Nakayama RT 1996 The effect of peritoneal fluid from patients with endometriosis on human sperm function in vitro. American Journal of Obstetrics and Gynecology 174 1779-1783; discussion 1783. (https://doi.org/10.1016/s0002-9378(96)70210-7)

Ambusaidi Q \& Jha C 2014 Pregnancy in the rudimentary uterine horn case report of an unusual presentation. Sultan Qaboos University Medical Journal 14 e134-e138. (https://doi.org/10.12816/0003349)

Burger MPM 2009 De aquatische conceptie. Nederlands Tijdschrift voor Obstetrie en Gynaecologie 122 245-250.

Dabirashrafi H, Moghadami-Tabrizi N \& Zandinejad K 1996 Laparoscopic ovarian transposition with subsequent intrauterine pregnancy. Journal of the American Association of Gynecologic Laparoscopists 3 515-517. (https://doi.org/10.1016/s1074-3804(05)80160-4)

De Graaf R 1686 Alle de wercken, so in de ontleed-kunde, als andere deelen der medicyne. Amsterdam: Abraham Abrahamse. English translation: Jocelyn HD, Setchell BP 1972 Regnier de Graaf on the human reproductive organs. An annotated translation of Tractatus de virorum organis generationi inservientibus (1668) and De mulierum organis generatori inservientibus tractatus novus (1672). Journal of Reproduction and Fertility 17 1-222. Oxford: Blackwell Publishing.

Donnez J, Dolmans MM, Demylle D, Jadoul P, Pirard C, Squifflet J, Martinez-Madrid B \& Van Langendonckt A 2004 Livebirth after orthotopic transplantation of cryopreserved ovarian tissue. Lancet 364 1405-1410. (https://doi.org/10.1016/S0140-6736(04)17222-X)

Donnez J, Martinez-Madrid B, Jadoul P, Van Langendonckt A, Demylle D \& Dolmans MM 2006 Ovarian tissue cryopreservation and transplantation: a review. Human Reproduction Update 12 519-535. (https://doi. org/10.1093/humupd/dml032)

Doyle JB 1951 Exploratory culdotomy for observation of tubo-ovarian physiology at ovulation time. Fertility and Sterility 2 475-486. (https:// doi.org/10.1016/s0015-0282(16)30721-x)

Doyle LL, Lippes J, Winters HS \& Margolis AJ 1966 Human ova in the Fallopian tube. American Journal of Obstetrics and Gynecology 95 115-117. (https://doi.org/10.1016/0002-9378(66)90637-5)

Farquhar C \& Marjoribanks J 2018 Assisted reproductive technology: an overview of cochrane reviews. Cochrane Database of Systematic Reviews 8 CD010537. (https://doi.org/10.1002/14651858.CD010537. pub5)

Ferrero S, Gillott DJ, Remorgida V, Anserini P, Ragni N \& Grudzinskas JG 2009 Proteomic analysis of peritoneal fluid in fertile and infertile women with endometriosis. Journal of Reproductive Medicine 54 32-40. 
First A 1954 Transperitoneal migration of ovum or spermatozoon. Obstetrics and Gynecology 4 431-434.

Forrler A, Dellenbach P, Nisand I, Moreau L, Cranz C, Clavert A \& Rumpler Y 1986 Direct intraperitoneal insemination in unexplained and cervical infertility. Lancet 1 916-917. (https://doi.org/10.1016/s01406736(86)91021-4)

Martínez-Román S, Balasch J, Creus M, Fábregues F, Carmona F, Vilella R \& Vanrell JA 1997 Transferrin receptor (CD71) expression in peritoneal macrophages from fertile and infertile women with and without endometriosis. American Journal of Reproductive Immunology $\mathbf{3 8}$ 413-417. (https://doi.org/10.1111/j.1600-0897.1997.tb00320.x)

Ombelet W, Cooke I, Dryer S, Serour G \& Devroey P 2008 Infertility and the provision of infertility medical services in developing countries. Human Reproduction Update 14 605-621. (https://doi.org/10.1093/ humupd/dmn042)

Sharma V, Pampiglione JS, Mason BA, Campbell S \& Riddle A 1991 Experience with peritoneal oocyte and sperm transfer as an outpatientbased treatment for infertility. Fertility and Sterility 55 579-582. (https:// doi.org/10.1016/s0015-0282(16)54189-2)

Skrzypczak J, Szczepanska M, Puk E, Kamieniczna M \& Kurpisz M 2005 Peritoneal fluid cytokines and sICAM-1 in minimal endometriosis: search for discriminating factors between infertility and/or endometriosis. European Journal of Obstetrics and Gynecology and Reproductive Biology 122 95-103. (https://doi.org/10.1016/j.ejogrb.2004.11.044)

Templeton AA \& Mortimer D 1980 Laparoscopic sperm recovery in infertile women. British Journal of Obstetrics and Gynaecology 87 1128-1131. (https://doi.org/10.1111/j.1471-0528.1980.tb04485.x)
Van der Borght M \& Wyns C 2018 Fertility and infertility: definition and epidemiology. Clinical Biochemistry 62 2-10. (https://doi.org/10.1016/j. clinbiochem.2018.03.012)

Van Der Ven H, Liebenthron J, Beckmann M, Toth B, Korell M, Krüssel J, Frambach T, Kupka M, Hohl MK, Winkler-Crepaz K et al. 2016 Ninetyfive orthotopic transplantations in 74 women of ovarian tissue after cutotoxis treatment in a fertility preservation network: tissue activity, pregnancy and delivery rates. Human Reproduction 31 2031-2041. (https://doi.org/10.1093/humrep/dew165)

Williams M, Hill CJ, Scudamore I, Dunphy B, Cooke ID \& Baratt CLR 1993 Sperm numbers and distribution within the human fallopian tube around ovulation. Human Reproduction 8 2019-2026. (https://doi.org/10.1093/ oxfordjournals.humrep.a137975)

Yildizhan R, Kolusari A, Adali F, Adali E, Kurdoglu M, Ozgokce C \& Cim N 2009 Primary abdominal ectopic pregnancy: a case report. Cases Journal 2 8485. (https://doi.org/10.4076/1757-1626-2-8485)

Received 4 July 2020

First decision 20 July 2020

Revised Manuscript received 29 September 2020

Accepted 6 October 2020 